\title{
A uniportal video-assisted thoracoscopic segmentectomy(S3) for left upper lobe
}

\author{
Min Cao, Xiaojing Zhao, Yujie Fu \\ Department of Thoracic Surgery, Renji Hospital, Shanghai Jiao Tong University School of Medicine, Shanghai, China \\ Correspondence to: Yujie Fu. Department of Thoracic Surgery, Renji Hospital, Shanghai Jiao Tong University School of Medicine, Shanghai 200127, \\ China. Email: richardjiejie@hotmail.com.
}

\begin{abstract}
A 62-year-old female presented with a mixed ground glass opacity (mGGO) at left upper lobe by computed tomography (CT) examination. The lesion had a size of $12 \mathrm{~mm}$ and a maximum CT value of $-450 \mathrm{HU}$. But more importantly, there were no obvious changes of the lesion observed after regular using of anti-inflammatory drugs. So, the lesion was diagnosed as an early non-small cell lung cancer (NSCLC). Surgical intervention is the treatment of choice for the patient. Preoperative three-dimensional reconstruction was performed to confirm that the lesion was located in the anterior segment (S3) of the left upper lobe. Meanwhile, the fact that solid components in the lesion were between $25 \%$ and $50 \%$ is which suggested a noninvasive cancer. Therefore, a S3 segment resection of the left upper lobe was performed by uniportal video-assisted thoracoscopic surgery (VATS). Hookwire was used to guide the exact position of the lesion before operation while the distribution of blood vessels and bronchi was identified in the threedimensional condition. Depending on the model of three-dimensional reconstruction, we successfully removed the S3 segment of left upper lobe without dissection of mediastinal lymph nodes. Minimally invasive adenocarcinoma was confirmed by pathology diagnosis. Here, we present a uniportal VATS of S3 segmentectomy.
\end{abstract}

Keywords: Uniportal video-assisted thoracoscopic surgery (uniportal VATS); S3 segmentectomy; 3D reconstruction

Received: 29 March 2020; Accepted: 22 December 2020; Published: 25 February 2022.

doi: $10.21037 /$ ccts-20-80

View this article at: http://dx.doi.org/10.21037/ccts-20-80

\section{Introduction}

Lobectomy is the standard treatment for early-stage non-small cell lung cancer. However, some studies have shown that segmentectomy can yield the same benefits in the treatment of early-stage lung cancer, especially for noninvasive group (1). In recent years, uniportal videoassisted thoracoscopic surgery (VATS) has been widely used in treatment of early-stage non-small cell lung cancer (NSCLC) after first reported by Gonzalez-Rivas (2). Here, a uniportal VATS of S3 segmentectomy without dissection of mediastinal lymph nodes is presented. All procedures performed in this study were in accordance with the ethical standards of the institutional and/or national research committee(s), and with the Helsinki Declaration (as revised in 2013). Written informed consent was obtained from the patient for publication of this study and accompanying images. A copy of the written consent is available for review by the editorial office of this journal.

\section{Surgical technique}

An enhanced chest computed tomography (CT) scan was completed before operation, which showed a lesion in the left upper lobe. The lesion was presented as a mixed ground glass opacity (mGGO) with a size of $12 \mathrm{~mm}$ and a maximum CT value of $-450 \mathrm{HU}$. The consolidation to tumor ratio $(\mathrm{C} / \mathrm{T})$ was 0.25 to 0.5 , which suggested that the lesion was a noninvasive adenocarcinoma according to the clinical research of JCOG1211 (3). Further, we confirmed that the lesion was located in anterior segment of left upper 


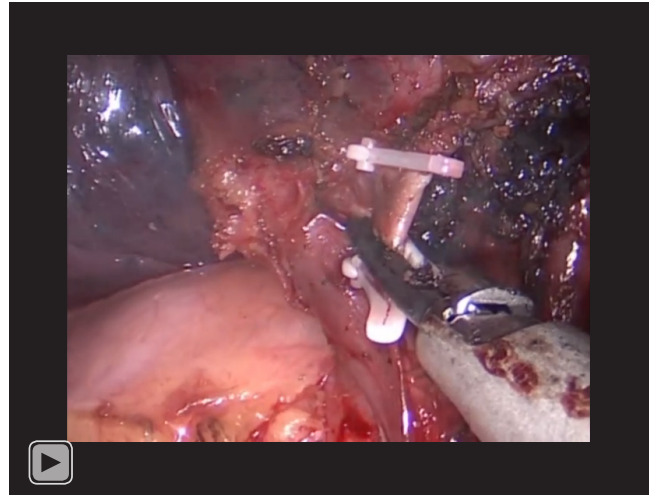

Video 1 A uniportal video-assisted thoracoscopic segmentectomy (S3) for left upper lobe.

lobe by the three-dimensional reconstruction technique, and the lesion had a safe distance to the resection margin in the preoperative planning. Base on the above conditions, a uniportal VATS of S3 segmental resection was performed (Video 1). The procedure was performed under general anesthesia with double lumen intubation, and the patient was placed in lateral decubitus position. A 3-cm incision was made at the $4^{\text {th }}$ intercostal between the left anterior axillary line and the mid-axillary line. A 10-mm camera of 30 degree should be placed to be close to the edge of the incision.

Firstly, mediastinal pleura neared by the left hilum of lung was opened by Harmonic, and the left superior pulmonary vein was exposed (Figure 1). And then, the sheath of left superior vein was removed to exposing the various branches of the vein (Figure 2). According to the reconstruction model, we determined the attribution of each branch of veins, and branch of $\mathrm{V}^{3} \mathrm{c}$ was the vein that we needed to cut off. The $V^{3} \mathrm{c}$ was clipped with Hemolok and cut off with Harmonic. Secondly, the $12^{\text {th }}$ lymph nodes were dissected in order to expose the bronchus $\left(\mathrm{B}^{1+2+3}\right)$ and $\mathrm{A}^{3}$ (Figure 3). The lung tissue was flipped over and the branch of $\mathrm{A}^{1+2}(\mathrm{a}+\mathrm{b})$ was dissociated (Figure 4). Then $\mathrm{A}^{3}$ artery was disconnected by stapler when the branch of $\mathrm{A}^{3}$ was identified. Afterwards, the branch of $\mathrm{B}^{3}$ was dissociated by Harmonic and disconnected by stapler. At last, the $\mathrm{S} 3$ intersegment plane was demarcated by inflation-deflation and divided with staplers (Figure 5). The lung was removed without mediastinal lymph nodes dissection.

\section{Comments}

The left upper pulmonary resection is more difficult than any other procedures due to the more variable of vessels of

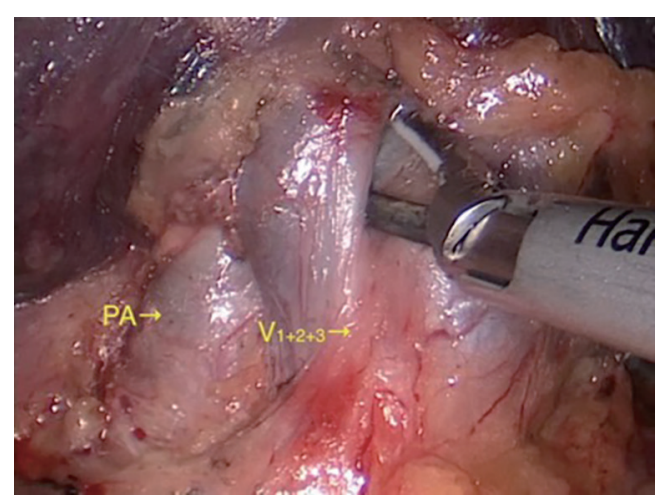

Figure 1 The left superior pulmonary vein was exposed.

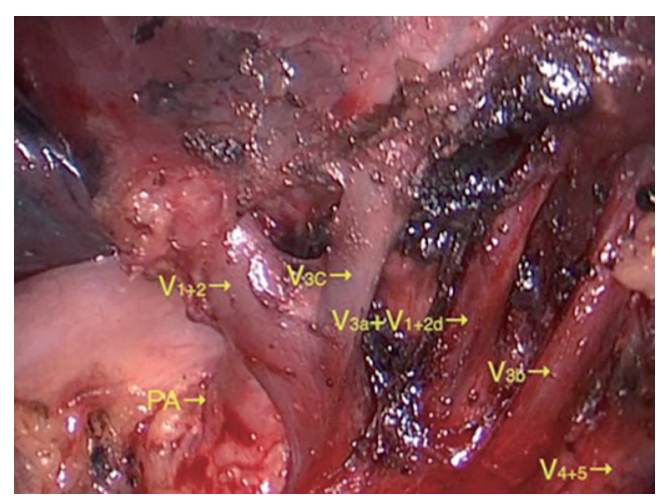

Figure 2 The sheath of left superior vein was removed.

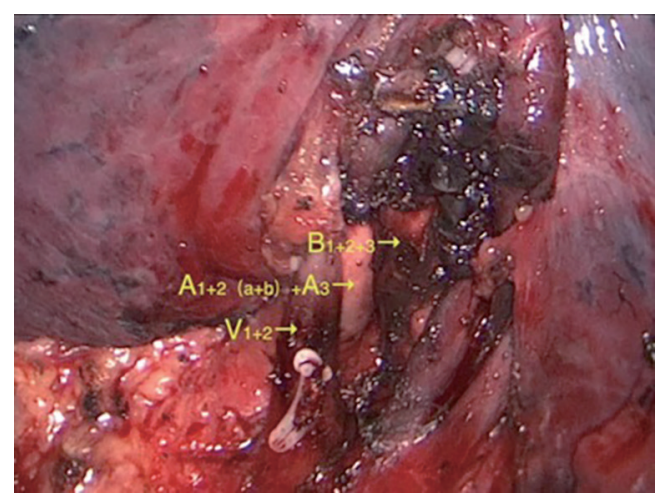

Figure 3 The bronchus $\left(\mathrm{B}^{1+2+3}\right)$ and $\mathrm{A}^{3}$ were exposed.

left lobe. In this being, the segmentectomy (S3) of left upper lobe is one of the most difficult operations of all pulmonary segments, especially in the condition of uniportal VATS. In this procedure, the most important thing is preserving the function of the adjacent lung segments $(\mathrm{S} 4+5$ and $\mathrm{S} 1+2)$. To do this, we need to deal with the $\mathrm{V}^{3} \mathrm{c}$ very carefully 


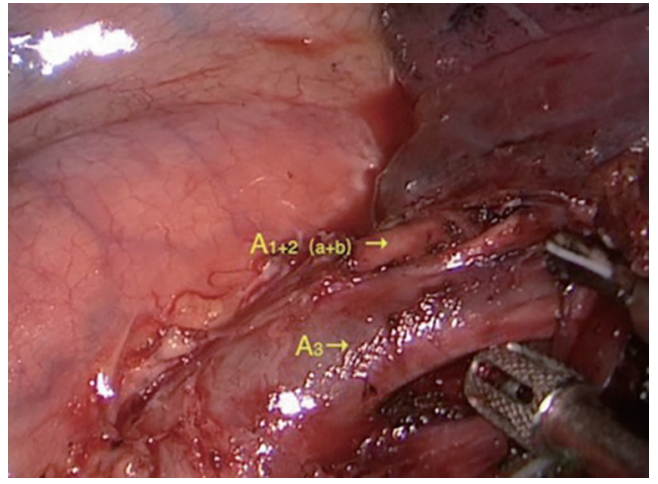

Figure 4 The lung tissue was flipped over and the branch of $\mathrm{A}^{1+2}(\mathrm{a}+\mathrm{b})$ was exposed.

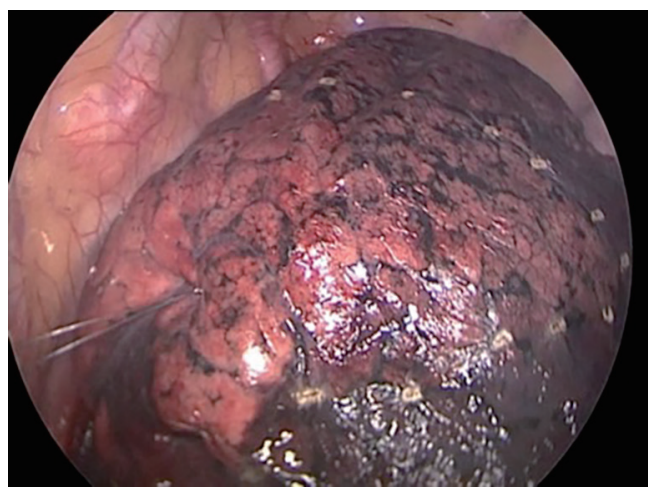

Figure 5 The S3 intersegment plane was demarcated.

and preserve the $\mathrm{V}^{3} \mathrm{~b}$ and $\mathrm{V}^{1+2}$ a quite well. The blood vessels of $\mathrm{V}^{3} \mathrm{~b}$ and $\mathrm{V}^{1+2}$ a as markers are used to identify the demarcation of S3. The three-dimensional reconstruction before operation is of great significance in segmentectomy (4), which can facilitate the identification of the hilar structures. This preoperation planning improves the accuracy of the anatomical resection. In the video, there is a fact that the dissection of group 12 lymph nodes is critical to exposing the branch of $\mathrm{A}^{3}$ and target bronchus. Actually, segmental lymph node is so fragile that rupture happens all the time during the free process. We need to pay more attention to lymph nodes dissection in segmentectomy. After that, we find $\mathrm{A}^{3}$ partly at the dorsal side of $\mathrm{V}^{1+2}$, which is limited by the field of view in uniportal operation. So, the lung tissue is flipped over and the branch of $\mathrm{A}^{3}$ is exposed clearly. It is worth noting that the variation of $\mathrm{A}^{4+5}$ or $\mathrm{A}^{5}$ (mediastinal lingual artery) may be encountered between $V^{3} c$ and $B^{3}$. The branch of $A^{3}$ artery can be disconnected by stapler when the absence of mediastinal lingual artery is confirmed. Now, the accompanying branch of bronchus $\left(\mathrm{B}^{3}\right)$ is obvious and disconnected by stapler. In generally, disconnection of $\mathrm{B}^{3}$ in left $\mathrm{S} 3$ segmentectomy is challenging because of the avoidance of $\mathrm{A}^{1+2}$ injury. In our medical center, the branch of $\mathrm{B}^{3}$ is spaced out by silk thread in the procedure. Of course, in few cases, the $\mathrm{A}^{1+2}$ is not completely hidden behind $\mathrm{B}^{3}$ due to variation. In this condition, we can insert the stapler directly and cut off the targeted bronchi. Then, we can remove the target lung tissue by staplers. Notably, inflation-deflation is mandatory before S3 segment is divided with staplers, which is a conventional method to demarcate the intersegmental planes. However, the inflation-deflation needs a long time to demarcate the intersegmental planes in operation. Moreover, this method is limited in chronic obstructive pulmonary disease (COPD) patients because of the poor diffusion function. In addition, this method may increase the difficulty of locating the lesion after resection, if there are a few solid components in the lesion. Recently, a novel method of intravenous injection of indocyanine green (ICG) has been used in segmentectomy (5), which could demarcate the intersegmental planes immediately. Further studies of ICG in segmentectomy setting will be necessary to prove feasibility.

In the uniportal procedure, the most difficulty is the interference of surgical instruments. Our experience suggests that the using of Harmonic can alleviate this problem. During the operation, Harmonic can play a number of roles other than as an energy instrument, which means less number of surgical instruments entering the chest cavity is needed and leads to less interference between the instruments. On one hand, the use of Harmonic in operation is safer than other energy instruments. On the other hand, Harmonic has a unique advantage of dealing with small blood vessels, which can cut off the small blood vessels and keep the surgical field of vision clear. In view of the above-mentioned advantages, Harmonic is widely used in thoracoscopic surgery in our medical center, especially in uniportal procedure.

\section{Acknowledgments}

The video was awarded second prize in the First International Lung Surgery Competition (2019 Masters of Lung Surgery). Funding: None.

\section{Footnote}

Peer Review File: Available at https://ccts.amegroups.com/ article/view/10.21037/ccts-20-80/prf 
Conflicts of Interest: All authors have completed the ICMJE uniform disclosure form (available at https://ccts. amegroups.com/article/view/10.21037/ccts-20-80/coif). The authors have no conflicts of interest to declare.

Ethical Statement: The authors are accountable for all aspects of the work in ensuring that questions related to the accuracy or integrity of any part of the work are appropriately investigated and resolved. All procedures performed in this study were in accordance with the ethical standards of the institutional and/or national research committee(s), and with the Helsinki Declaration (as revised in 2013). Written informed consent was obtained from the patient for publication of this study and accompanying images. A copy of the written consent is available for review by the editorial office of this journal.

Open Access Statement: This is an Open Access article distributed in accordance with the Creative Commons Attribution-NonCommercial-NoDerivs 4.0 International License (CC BY-NC-ND 4.0), which permits the noncommercial replication and distribution of the article with the strict proviso that no changes or edits are made and the original work is properly cited (including links to both the formal publication through the relevant

doi: $10.21037 /$ ccts-20-80

Cite this article as: Cao M, Zhao X, Fu Y. A uniportal videoassisted thoracoscopic segmentectomy(S3) for left upper lobe. Curr Chall Thorac Surg 2022;4:10.
DOI and the license). See: https://creativecommons.org/ licenses/by-nc-nd/4.0/.

\section{References}

1. Koike T, Kitahara A, Sato S, et al. Lobectomy Versus Segmentectomy in Radiologically Pure Solid SmallSized Non-Small Cell Lung Cancer. Ann Thorac Surg 2016;101:1354-60.

2. Gonzalez-Rivas D, Fernandez R, Fieira E, et al. Uniportal video-assisted thoracoscopic bronchial sleeve lobectomy: first report. J Thorac Cardiovasc Surg 2013;145:1676-7.

3. Aokage K, Saji H, Suzuki K, et al. A non-randomized confirmatory trial of segmentectomy for clinical T1N0 lung cancer with dominant ground glass opacity based on thin-section computed tomography (JCOG1211). Gen Thorac Cardiovasc Surg 2017;65:267-72.

4. Xu G, Chen C, Zheng W, et al. Application of the IQQA$3 \mathrm{D}$ imaging interpretation and analysis system in uniportal video-assisted thoracoscopic anatomical segmentectomy: a series study. J Thorac Dis 2019;11:2058-66.

5. Motono N, Iwai S, Funasaki A, et al. Low-dose indocyanine green fluorescence-navigated segmentectomy: prospective analysis of 20 cases and review of previous reports. J Thorac Dis 2019;11:702-7. 